\title{
Hypoxia-inducible factor-1 $\alpha$ enhances the malignant phenotype of multicellular spheroid HeLa cells in vitro
}

\author{
XUN TIAN $^{1,2}$, WEI WANG ${ }^{2}$, QINGHUA ZHANG $^{1}$, LIANGPING ZHAO ${ }^{2}$, JUNCHEN WEI $^{2}$, \\ HUI XING ${ }^{2}$, YUPING SONG ${ }^{3}$, SHIXUAN WANG ${ }^{2}$, DING MA $^{2}, \mathrm{LI} \mathrm{MENG}^{2}$ and GANG CHEN ${ }^{2}$ \\ ${ }^{1}$ Central Hospital of Wuhan City; ${ }^{2}$ Cancer Biology Research Center, Tongji Hospital, Tongji Medical College, \\ Huazhong University of Science and Technology; ${ }^{3}$ Donghu Hospital of Wuhan City, Hubei, P.R. China
}

Received April 27, 2010; Accepted June 25, 2010

DOI: 10.3892/ol_00000159

\begin{abstract}
The purpose of this study was to clarify the direct effect of hypoxia-inducible factor- $1 \alpha$ (HIF-1 $\alpha)$ on tumor growth, apoptosis and migration in vitro. To achieve this aim, a comparison was made of the differences in growth rates, apoptotic indices and cell invasive ability in the human cervical cancer cell line HeLa and the HIF-1 $\alpha$-blocked counterpart in a three-dimensional spheroid culture. A significant decrease in cell proliferation and invasion, and an increase in cell apoptosis were observed in HIF-1 $\alpha$-blocked cells in the three-dimensional culture. The data indicated that a multicellular spheroid culture is an ideal model of hypoxia in vitro and that HIF-1 $\alpha$ is a significant regulator of adaptive processes that promote tumor cell malignant phenotypes, such as proliferation, anti-apoptosis and invasive ability.
\end{abstract}

\section{Introduction}

Tumor hypoxia is a significant factor in tumor physiology and treatment, as it appears to be closely associated with tumorigenesis, metastasis and chemoresistance (1). Hypoxia is a common characteristic of locally advanced solid tumors. Under this condition, reduced oxygen levels (hypoxia) lead to a set of cellular adaptations, including increased angiogenesis, erythropoiesis and a switch to glycolytic metabolism. Mounting evidence indicates that the effect of hypoxia on malignant progression is mediated by a series of hypoxia-induced proteomic and genomic changes that activate angiogenesis, anaerobic metabolism and other processes that enable tumor cells to survive or escape their oxygen-deficient environment. The critical regulatory gene that functions when

Correspondence to: Dr Gang Chen, Cancer Biology Research Center, Tongji Hospital, Tongji Medical College, Huazhong University of Science and Technology, 1095 Jiefang Ave., Wuhan, Hubei 430030, P.R. China

E-mail: gumpc@126.com

Key words: hypoxia-inducible factor-1 $\alpha$, cell invasion, apoptosis, cervical cancer the oxygen level in tissues is low is the transcription factor hypoxia-inducible factor-1 (HIF-1) (2,3). Clinical studies have suggested that HIF-1 is a significant regulator of tumor cell adaptation to hypoxic stress and is crucial in cervical malignant progression and outcome (4,5). HIF-1 plays an essential role in the maintenance of oxygen homeostasis in metazoan organisms (3). The DNA binding complex of HIF-1 is a heterodimer comprising HIF-1 $\alpha$ and HIF-1 $\beta$ subunits, both of which are basic helix-loop-helix transcription factors (6). HIF-1 $\alpha$ is constitutively expressed (7), but under normoxic conditions is hydroxylated at specific proline residues resulting in ubiquitination through the interaction with von HippelLindau factor suppressor protein (pVHL) and proteosomal degradation $(8,9)$. Under hypoxic conditions, proline hydroxylation is inhibited, preventing association with pVHL. Subsequently, HIF-1 $\alpha$ accumulates and associates with HIF-1 $\beta$ to form a heterodimer that accumulates in the nucleus and activates a specific set of genes by binding to hypoxic response elements in the promoter region (10). The HIF-1 $\alpha$ protein complex mediates transcriptional responses to hypoxia by binding to hypoxia response elements on specific target genes (2), but the role of HIF-1 in tumor growth and development remains uncertain as a number of in vivo studies have drawn conflicting results. For example, certain studies have shown that the loss of HIF-1 function inhibits both angiogenesis and tumor growth (11-13), while other studies showed impaired growth ability, but no effect on angiogenesis (12,14-16). The main reason for this phenomenon appears to be that HIF is not expressed in monolayer culture cells under normal culture circumstances. Therefore, the appropriate in vitro model simulating the realistic situation in vivo is the most important factor in the study of HIF functional analysis.

In this study, the three-dimensional spheroid culture method was employed to study the possible role of HIF-1 $\alpha$ in the biological behavior of the cervical tumor cell line HeLa in vitro. A vector was constructed to express antisense HIF-1 $\alpha$ (anti-HIF-1 $\alpha$-pEGFP) and transfect the latter into HeLa cells. Cell proliferation, apoptosis and migration were compared among the anti-HIF-1 $\alpha$-pEGFP-transfected (HIF-1 $\alpha$-blocked), pEGFP-transfected (mock, as a plasmid-transfection control) and untransfected cells. HIF-1 $\alpha$ was found to play a potentially pivotal role in the malignant phenotype of HeLa cells in vitro. 


\section{Materials and methods}

Cell culture. The human cervical carcinoma HeLa cell line was obtained from the American Type Culture Collection (ATCC, VA, Manassas, USA) and was cultured in RPMI growth medium supplemented with $10 \%$ fetal bovine serum (FBS). Cells were maintained at $37^{\circ} \mathrm{C}$ in a humidified atmosphere with $5 \% \mathrm{CO}_{2}$. For the hypoxic culture, cells were maintained in an incubator with $1 \% \mathrm{O}_{2}$.

Vector construction. RNA was isolated from HeLa cells using TRIzol ${ }^{\mathrm{TM}}$ Reagent (Gibco BRL, USA) according to the manufacturer's instructions. RNA $(2 \mu \mathrm{g})$ was used for cDNA synthesis by reverse transcription. The RNA samples were incubated at $70^{\circ} \mathrm{C}$ for $5 \mathrm{~min}$ with $0.5 \mu \mathrm{g}$ oligo(deoxythymidine) primers in a final volume of $10 \mu \mathrm{l}$ and then at $37^{\circ} \mathrm{C}$ for $60 \mathrm{~min}$ in a $25-\mu 1$ reaction volume containing $125 \mathrm{mmol} / 1$ deoxynucleotide triphosphate, 200 units Muloney murine leukemia virus reverse transcriptase and Muloney murine leukemia virus RT buffer (Promega, USA). The cDNAs obtained were amplified by using the cloning primers: 5' CGG GAT CCG GTG ATT TGG ATA TTG AAG ATG AC 3' (upper) and 5' GAA GAT CTC ACT CAC AAC GTA ATT CAC ACA TA 3' (lower). The PCR profile was $95^{\circ} \mathrm{C}$ for $1 \mathrm{~min}, 94^{\circ} \mathrm{C}$ for $40 \mathrm{sec}, 58^{\circ} \mathrm{C}$ for $40 \mathrm{sec}$ and $72^{\circ} \mathrm{C}$ for $1 \mathrm{~min}$ for 30 cycles, followed by extension for $7 \mathrm{~min}$ at $72^{\circ} \mathrm{C}$. The amplified products were purified using a PCR kit (New England Biotech, UK), ligated with pEGFP vector (Promega) by following the instruction manual. The recombinant plasmid was then screened by digestion and sequencing to confirm the blocked sequences of HIF-1, and was termed anti-HIF-1 $\alpha$-pEGFP.

Vector transfection and clone selection. HeLa cells were transfected with $3 \mu \mathrm{g}$ pEGFP (as a blank control) or $3 \mu \mathrm{g}$ anti-HIF-1 $\alpha$-pEGFP according to the protocol provided with the Lipofectamine 2000 transfection reagent (Life Technologies, Inc.). Briefly, $2 \times 10^{5}$ cells were plated in 6-well plates and incubated with the appropriate plasmid DNA and Lipofectamine 2000 in serum-free medium for $5 \mathrm{~h}$. Equal volumes of media containing $20 \%$ FBS were then added. After $24 \mathrm{~h}$, the media were replaced with media containing 1 $\mathrm{mg} / \mathrm{ml} \mathrm{G} 418$. Surviving colonies were selected after 2 weeks and maintained in $300 \mu \mathrm{g} / \mathrm{ml} \mathrm{G} 418$. Positive cell clones were selected and amplified. Changes in HIF-1 $\alpha$ levels were confirmed by Western blotting in the hypoxic environment.

Spheroid culture. HeLa cells, the anti-HIF-1 $\alpha$-pEGFP transfected counterpart and the control blank vector-transfected cells were cultured to $95 \%$ confluence, seeded into agarosecoated 24-well plates at a density of 2,000 cells/well and cultured. Each well contained $200 \mu \mathrm{l}$ of tissue culture medium, and the spheroids were fed every other day by carefully aspirating $100 \mu \mathrm{l}$ of spent medium and replacing it with the same quantity of fresh medium.

Western blot analysis. Cells were lysed in a lysis buffer containing $50 \mathrm{~mm}$ Tris, $\mathrm{pH} 7.4,150 \mathrm{~mm} \mathrm{NaCl}, 0.5 \%$ NP-40, $50 \mathrm{~mm} \mathrm{NaF}, 1 \mathrm{~mm} \mathrm{Na}_{3} \mathrm{VO}_{4}, 1 \mathrm{~mm}$ phenylmethylsulfonyl fluoride, $25 \mathrm{mg} / \mathrm{ml}$ leupeptin and $25 \mathrm{mg} / \mathrm{ml}$ aprotinin. The lysates were cleared by centrifugation, and the supernatants were

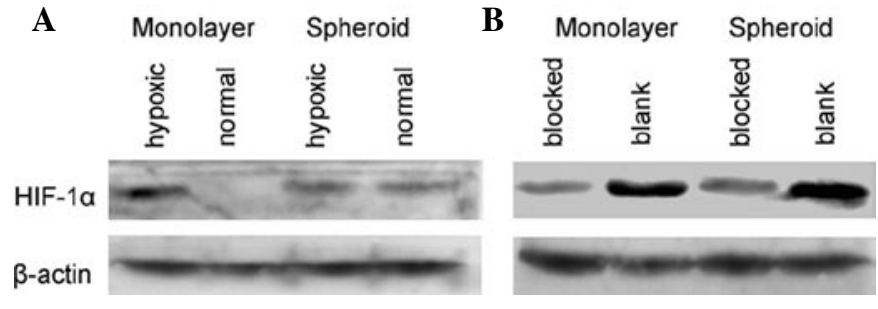

Figure 1. (A) HIF-1 $\alpha$ protein was expressed in the hypoxic culture or normal spheroid culture but was not expressed under normal culture conditions. (B) Significantly decreased HIF-1 $\alpha$ expression was noted in the anti-HIF-1 $\alpha$ pEGFP-transfected (blocked) HeLa cells in hypoxic conditions compared to the blank pEGFP vector-transfected cells in the monolayer culture. Similar results were also obtained in the multicellular spheroids.

collected. Equal amounts of lysate protein were used for the Western blot analyses with the indicated antibodies. Specific signals were visualized using the ECL chemiluminescence detection kit (Amersham, Arlington Heights, IL, USA).

Analysis of cell proliferation and apoptosis by flow cytometry. After trypsinization for cell detachment, the cells were incubated in 50\% FBS for $15 \mathrm{~min}$ to restore membrane integrity and centrifuged for $5 \mathrm{~min}$ at 1,200 rpm. Detached cells were stored via retention of the culture medium and recovered by centrifugation. Apoptotic cells were detected by assaying the Annexin $\mathrm{V}$ binding by flow cytometry (commercially available test, provided by Boehringer Mannheim). To exclude necrotic cells, we double-stained the cells with $5 \mu \mathrm{g} / \mathrm{ml}$ propidium iodide (PI) in PBS. Cells were fixed with $75 \%$ ethanol and digested with DNase-free RNase in PBS containing $5 \mu \mathrm{g} / \mathrm{ml}$ PI for DNA staining for $45 \mathrm{~min}$ at $37^{\circ} \mathrm{C}$. PI and forward light scattering were detected using the flow cytometer FACSCalibur (Beckton-Dickinson) equipped with Cell Quest software. The data were analyzed using Cell Fit software. The experiment was repeated three times.

Spheroid invasion assays. Cell motility was assessed using the HABM-HEC model. Multicellular spheroids were plated at 100 spheroids/well in the upper chamber of the model. The outer chambers were filled with $0.5 \mathrm{ml}$ of media containing $10 \%$ FBS. After $24 \mathrm{~h}$, cells migrating to the undersurface of the filters were counted. The same five microscopic fields were used to count the number of cells passing to the undersurface of each filter.

Statistical analysis. All experiments were repeated at least three times. The Student's t-test was used to evaluate the differences between the experimental and control groups. $\mathrm{P}<0.05$ was considered to be statistically significant.

\section{Results}

Expression of HIF-1 $\alpha$ protein in the monolayer-cultured HeLa cells and the multicellular spheroids. In the monolayercultured HeLa cells, no HIF-1 $\alpha$ protein expression was detected under normal culture conditions. However, we observed HIF-1 $\alpha$ expression under hypoxic conditions. Nevertheless, in the multicellular tumor spheroids, HIF-1 $\alpha$ was expressed in hypoxic and normal cultures (Fig. 1A). 


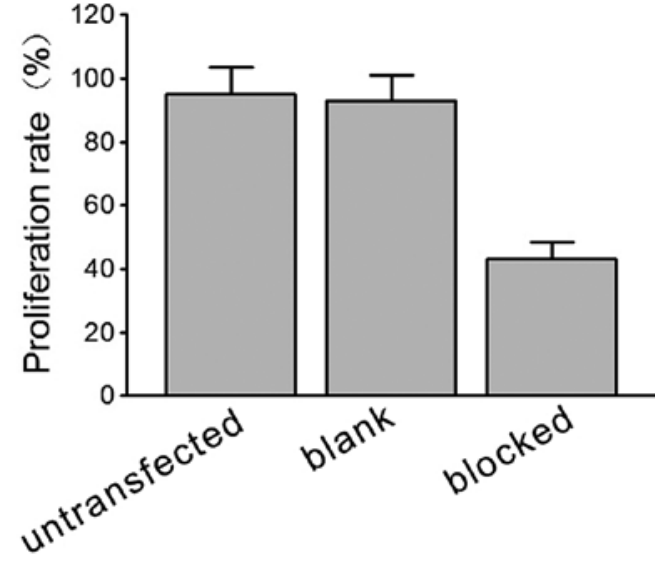

Figure 2. A marked decrease in proliferation was observed in the HeLa cell spheroids when compared to the blank pEGFP vector-transfected spheroid cells under normal culture conditions.

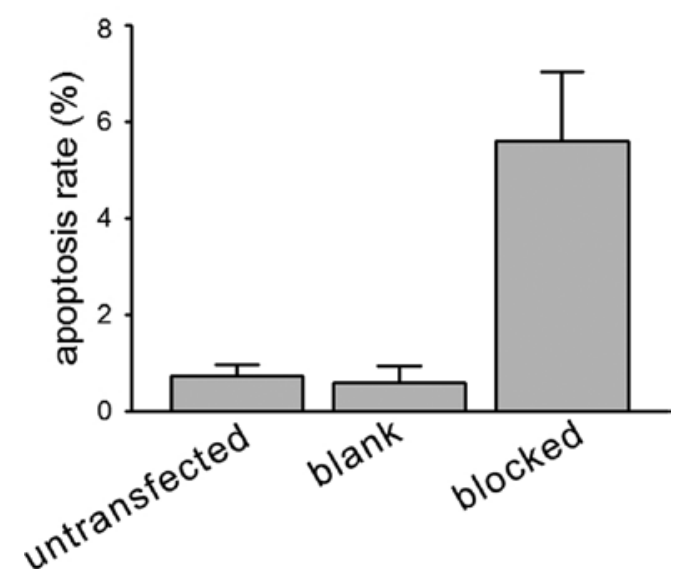

Figure 3. HIF-1 $\alpha$-blocked HeLa cell spheroids had higher fold levels of apoptosis than those of the blank vector-transfected cell spheroids in the normal culture.

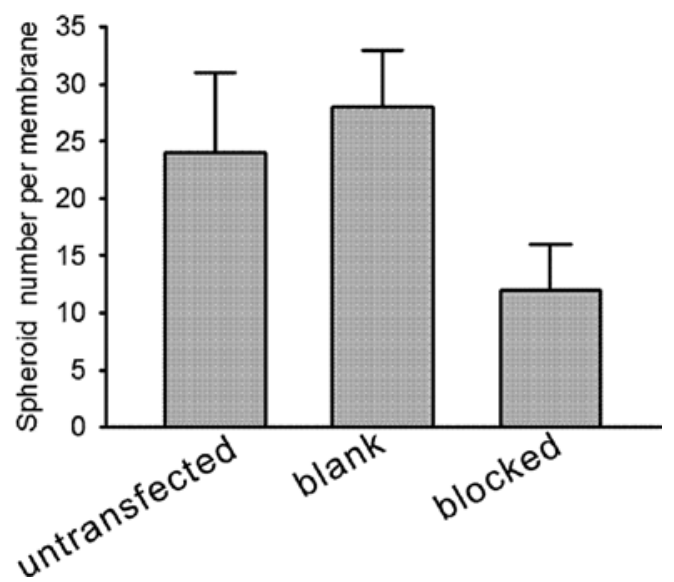

Figure 4. The rate of invasion of the HIF-1 $\alpha$-blocked HeLa cells was much lower than that of the blank vector-transfected HeLa cells in the spheroids under normal conditions.

A significantly decreased HIF-1 $\alpha$ expression was noted in the anti-HIF-1 $\alpha$-pEGFP-transfected (blocked) HeLa cells under hypoxic conditions, compared to the blank pEGFP vector- transfected cells in the monolayer culture. Similar results were also obtained in the multicellular spheroids (Fig. 1B). These results confirm that HIF-1 $\alpha$ is expressed under hypoxic conditions and that the multicellular tumor spheroid was an ideal model of hypoxia in vitro.

Effect of HIF-1 $\alpha$ on multicellular spheroid growth and apoptosis. In the HIF-1 $\alpha$-blocked HeLa cells, a marked decrease in proliferation was observed in the HeLa cell spheroids when compared to the blank pEGFP vector-transfected spheroid cells under normal culture conditions, as assessed by flow cytometry and the counting of cell numbers (Fig. 2).

Concomitantly, when the apoptotic indices were compared, HIF-1 $\alpha$-blocked HeLa cell spheroids had higher fold levels of apoptosis than those of the blank vector-transfected cell spheroids (5.6 vs. $0.6 \%$ ) in the normal culture (Fig. 3).

HIF-1 $\alpha$ protein promotes the invasive ability of HeLa cells. To evaluate the effect of HIF-1 $\alpha$ on cell invasive ability, an invasion assay was performed in vitro by testing the cells invading from the top well to the lower chamber. Our data showed that the invasion rate of the HIF-1 $\alpha$-blocked HeLa cells was much lower than that of the blank vector-transfected HeLa cells in the spheroids under normal conditions (Fig. 4, $\mathrm{P}<0.01$ ). Findings of this study indicate that HIF-1 $\alpha$ protein promotes the invasive activity of tumor cells in a three-dimensional spheroid culture in vitro.

\section{Discussion}

Cells under hypoxic conditions express a series of genes that allow for survival and proliferation. HIF-1 $\alpha$ regulates the expression of more than 30 target genes (11), most of which play roles in tumor malignant behaviors, such as proliferation, invasion and metastasis (17,18). HIF-1 $\alpha$ expression is a common feature of solid human tumors and has been reported in many different tumor types $(5,19-25)$. Moreover, the overexpression of HIF-1 $\alpha$ was found to be a poor prognostic indicator in a variety of tumors $(4,26-28)$.

This study focused on whether HIF-1 $\alpha$ is involved in the cervical tumor malignant phenotype by affecting proliferation, apoptosis and tumor invasion of HeLa cells in vitro. Therefore, we established interference for the inhibition of HIF-1 $\alpha$ in HeLa cells. Since HIF-1 $\alpha$ rapidly undergoes ubiquitin-mediated degradation during normoxia, we detected HIF-1 $\alpha$ expression in monolayer cultured cells and in multicellular spheroids, respectively. HIF-1 $\alpha$ was not detected in HeLa cells in the monolayer culture in a normal culture condition. However, it displayed a strong increase at the protein level in multicellular spheroids under the same condition or in a monolayer under hypoxic conditions. The main cause of this phenomenon may be that in three-dimensional spheroid culture, oxygen diffusion was limited by the depth of the fluid medium and the smaller surface area to the volume compared to that in monolayer culture cells. Thus, the spheroid culture is an ideal model for the study of the mechanism of HIF-1 $\alpha$ in vitro.

We transfected the antisense HIF- $1 \alpha$ plasmid into the human cervical cancer cell line HeLa. Western blotting showed that the HIF-1 $\alpha$ expression was markedly down-regulated in the cloned antisense plasmid-transfected cells in the mono- 
layer under a hypoxic condition or in multicellular spheroids in a normal culture condition.

We then compared the cell proliferation between HIF-1 $\alpha$ blocked and blank plasmid-transfected cells. We found that spheroid HIF-1 $\alpha$-blocked HeLa cells decreased proliferative ability when compared to the blank plasmid-transfected cells in the normal culture condition. The apoptotic rate of HIF-1 $\alpha$ blocked cells was also significantly reduced in the spheroid cultured cells when compared to the monolayer cultured cells. Additionally, the HIF-1 $\alpha$-blocked HeLa cell spheroids had higher fold levels of apoptosis than the normal HeLa cells $(5.6 \%$ of cells in the HIF-1 $\alpha$-blocked HeLa cell spheroids compared to $0.6 \%$ in the HeLa cells). Thus, in the spheroids, HIF-1 $\alpha$ has a dual role in the regulation of cell division and resistance to apoptosis. Studies have reported that hypoxia causes cell death partly by involving the pro-apoptotic HIF-regulated factor BNip3 (26,29,30). Nevertheless, in spheroids, overall HIF-1 has an anti-apoptotic effect as measured by the inhibition of caspase- 3 activation in the proliferating compartment and by the final growth rate of the spheroid (31).

When the cell cycle was analyzed, enhanced transition from the $\mathrm{G} 1$ into the $\mathrm{S}$ phase was noted under hypoxic conditions. However, Wang et al (32) showed that the loss of HIF-1 $\alpha$ caused an increased progression into the $\mathrm{S}$ phase and abolished hypoxia-induced growth arrest. Goda et al found that HIF-1 $\alpha$ was required for cell cycle arrest during hypoxia and that BrdUrd labeling was increased in HIF-1 $\alpha$ null B cells in culture (33), which was also observed in HIF-1 $\alpha$ null chondrocytes in vivo (34). Taken together, the findings appear to be contradictory to our observation that the overall growth rate was slower in the anti-HIF-1 $\alpha$ HeLa spheroids. Other studies have shown that HIF-1 $\alpha$-defective tumor cell lines grow more quickly than those with functional HIF-1 $\alpha$ in normoxia (12). However, we observed no difference in the growth rates of the HeLa and HIF-1 dysfunctional HeLa cell lines in the normoxic monolayer culture.

HIF-1 $\alpha$ protein has been found to be overexpressed in multiple types of human cancer and distant metastatic tissues (18). This overexpression of HIF-1 $\alpha$ may occur very early in carcinogenesis before histological evidence of angiogenesis or invasion (18). Regarding cell migration, the data presented in this study suggest a molecular mechanism by decreasing the protein level of HIF- $1 \alpha$ as an anti-metastatic strategy. However, the discrepancy between the extent by which antiHIF-1 $\alpha$ decreases the HIF-1 $\alpha$ level and expression levels of its target genes must be considered. Transactivation of target genes by HIF-1 $\alpha$ is cell-type specific; thus, it should not be expected that the same battery of genes reported would be transactivated by HIF-1 $\alpha$ in other cell lines. Furthermore, the data presented in this study did not distinguish between direct and indirect regulation of the identified target genes by HIF-1 $\alpha$. Nevertheless, our results indicate that antisense affects multiple steps in the complex process of invasion by inhibiting HIF-1 $\alpha$.

This study therefore supports the hypothesis that HIF-1 $\alpha$ is a significant regulator of adaptive processes that promote tumor cell malignant phenotypes, such as proliferation, anti-apoptosis and invasive ability. The results of previous pre-clinical and clinical studies have established the theory that tumor hypoxia may promote malignant progression by a number of mechanisms, including an increased expression of transcription factors and gene products involved in tumor propagation and the induction of genomic instability. Therefore, in developing treatment strategies for cancer patients, it is reasonable to consider approaches aimed at ameliorating tumor hypoxia in an effort to maximize the effects of cancer therapy.

\section{Acknowledgements}

This study was supported by the National Science Foundation of China (nos. 30700895, 30770913, 30571950, 30271358 and 30370657); Major Innovation Medicine program (2009ZX09103738) and the '973' Program of China (no. 2009CB521808).

\section{References}

1. Hockel M and Vaupel P: Tumor hypoxia: definitions and current clinical, biologic, and molecular aspects. J Natl Cancer Inst 93: 266-276, 2001

2. Semenza GL: Life with oxygen. Science 318: 62-64, 2007.

3. Brahimi-Horn MC and Pouyssegur J: Harnessing the hypoxiainducible factor in cancer and ischemic disease. Biochem Pharmacol 73: 450-457, 2007.

4. Bachtiary B, Schindl M, Potter R, et al: Overexpression of hypoxia-inducible factor 1alpha indicates diminished response to radiotherapy and unfavorable prognosis in patients receiving radical radiotherapy for cervical cancer. Clin Cancer Res 9: 2234-2240, 2003.

5. Birner P, Schindl M, Obermair A, Plank C, Breitenecker G and Oberhuber G: Overexpression of hypoxia-inducible factor 1alpha is a marker for an unfavorable prognosis in early-stage invasive cervical cancer. Cancer Res 60: 4693-4696, 2000.

6. Giordano FJ and Johnson RS: Angiogenesis: the role of the microenvironment in flipping the switch. Curr Opin Genet Dev 11: 35-40, 2001.

7. Huang LE, Arany Z, Livingston DM and Bunn HF: Activation of hypoxia-inducible transcription factor depends primarily upon redox-sensitive stabilization of its alpha subunit. J Biol Chem 271: 32253-32259, 1996.

8. Maxwell PH, Wiesener MS, Chang GW, et al: The tumour suppressor protein VHL targets hypoxia-inducible factors for oxygen-dependent proteolysis. Nature 399: 271-275, 1999.

9. Cockman ME, Masson N, Mole DR, et al: Hypoxia inducible factor-alpha binding and ubiquitylation by the von HippelLindau tumor suppressor protein. J Biol Chem 275: 25733-25741, 2000.

10. Jiang BH, Rue E, Wang GL, Roe $\mathrm{R}$ and Semenza GL: Dimerization, DNA binding, and transactivation properties of hypoxia-inducible factor 1. J Biol Chem 271: 17771-17778, 1996.

11. Maxwell PH, Dachs GU, Gleadle JM, et al: Hypoxia-inducible factor-1 modulates gene expression in solid tumors and influences both angiogenesis and tumor growth. Proc Natl Acad Sci USA 94: 8104-8109, 1997.

12. Hopfl G, Wenger RH, Ziegler U, et al: Rescue of hypoxia-inducible factor-1alpha-deficient tumor growth by wild-type cells is independent of vascular endothelial growth factor. Cancer Res 62: 2962-2970, 2002.

13. Kung AL, Wang S, Klco JM, Kaelin WG and Livingston DM: Suppression of tumor growth through disruption of hypoxiainducible transcription. Nat Med 6: 1335-1340, 2000.

14. Ryan HE, Lo J and Johnson RS: HIF-1 alpha is required for solid tumor formation and embryonic vascularization. EMBO J 17: 3005-3015, 1998.

15. Ryan HE, Poloni M, McNulty W, et al: Hypoxia-inducible factorlalpha is a positive factor in solid tumor growth. Cancer Res 60: 4010-4015, 2000.

16. Chen J, Zhao S, Nakada K, et al: Dominant-negative hypoxiainducible factor-1 alpha reduces tumorigenicity of pancreatic cancer cells through the suppression of glucose metabolism. Am J Pathol 162: 1283-1291, 2003.

17. Erler JT, Bennewith KL, Nicolau M, et al: Lysyl oxidase is essential for hypoxia-induced metastasis. Nature 440: 1222-1226, 2006. 
18. Liao D, Corle C, Seagroves TN and Johnson RS: Hypoxiainducible factor-1alpha is a key regulator of metastasis in a transgenic model of cancer initiation and progression. Cancer Res 67: 563-572, 2007.

19. Giatromanolaki A, Koukourakis MI, Sivridis E, et al: Relation of hypoxia inducible factor 1 alpha and 2 alpha in operable non-small cell lung cancer to angiogenic/molecular profile of tumours and survival. Br J Cancer 85: 881-890, 2001.

20. Talks KL, Turley H, Gatter KC, et al: The expression and distribution of the hypoxia-inducible factors HIF-1alpha and HIF-2alpha in normal human tissues, cancers, and tumorassociated macrophages. Am J Pathol 157: 411-421, 2000.

21. Blancher C, Moore JW, Talks KL, Houlbrook S and Harris AL: Relationship of hypoxia-inducible factor (HIF)-1alpha and HIF-2alpha expression to vascular endothelial growth factor induction and hypoxia survival in human breast cancer cell lines. Cancer Res 60: 7106-7113, 2000.

22. Koukourakis MI, Giatromanolaki A, Sivridis E, et al: Hypoxiainducible factor (HIF1A and HIF2A), angiogenesis, and chemoradiotherapy outcome of squamous cell head-and-neck cancer. Int J Radiat Oncol Biol Phys 53: 1192-1202, 2002.

23. Koukourakis MI, Giatromanolaki A, Skarlatos J, et al: Hypoxia inducible factor (HIF-1 $\alpha$ and HIF-2 $\alpha$ ) expression in early esophageal cancer and response to photodynamic therapy and radiotherapy. Cancer Res 61: 1830-1832, 2001.

24. Sermeus A, Cosse JP, Crespin M, et al: Hypoxia induces protection against etoposide-induced apoptosis: molecular profiling of changes in gene expression and transcription factor activity. Mol Cancer 7: 27, 2008.

25. Zhong H, De Marzo AM, Laughner E, et al: Overexpression of hypoxia-inducible factor lalpha in common human cancers and their metastases. Cancer Res 59: 5830-5835, 1999.

26. Peng XH, Karna P, Cao Z, Jiang BH, Zhou M and Yang L: Cross-talk between epidermal growth factor receptor and hypoxia-inducible factor-1alpha signal pathways increases resistance to apoptosis by up-regulating survivin gene expression. J Biol Chem 281: 25903-25914, 2006.
27. Shibaji T, Nagao M, Ikeda N, et al: Prognostic significance of HIF-1 alpha overexpression in human pancreatic cancer. Anticancer Res 23: 4721-4727, 2003.

28. Bos R, van der Groep P, Greijer AE, et al: Levels of hypoxiainducible factor-1alpha independently predict prognosis in patients with lymph node negative breast carcinoma. Cancer 97: 1573-1581, 2003.

29. Ramanathan M, Luo W, Csoka B, et al: Differential regulation of HIF-1alpha isoforms in murine macrophages by TLR4 and adenosine $\mathrm{A}(2 \mathrm{~A})$ receptor agonists. J Leukoc Biol 86: 681-689, 2009.

30. Zheng X, Ruas JL, Cao R, et al: Cell-type-specific regulation of degradation of hypoxia-inducible factor 1 alpha: role of subcellular compartmentalization. Mol Cell Biol 26: 4628-4641, 2006.

31. Leek RD, Stratford I and Harris AL: The role of hypoxiainducible factor-1 in three-dimensional tumor growth, apoptosis, and regulation by the insulin-signaling pathway. Cancer Res 65 : 4147-4152, 2005

32. Wang G, Reisdorph R, Clark RE Jr, Miskimins R, Lindahl R and Miskimins WK: Cyclin dependent kinase inhibitor p27(Kip1) is upregulated by hypoxia via an ARNT dependent pathway. J Cell Biochem 90: 548-560, 2003.

33. Goda N, Ryan HE, Khadivi B, McNulty W, Rickert RC and Johnson RS: Hypoxia-inducible factor lalpha is essential for cell cycle arrest during hypoxia. Mol Cell Biol 23: 359-369, 2003.

34. Schipani E, Ryan HE, Didrickson S, Kobayashi T, Knight M and Johnson RS: Hypoxia in cartilage: HIF-1alpha is essential for chondrocyte growth arrest and survival. Genes Dev 15: 2865-2876, 2001. 